\title{
A DISPUTA DOS RECURSOS PÚBLICOS DA EDUCAÇÃO BÁSICA, OS ARRANJOS DO ESTADO COM O MERCADO E SEUS IMPACTOS NA GESTÃO DEMOCRÁTICA E PARTICIPATIVA DA EDUCAÇÃO NO ÂMBITO DOS MUNICÍPIOS
}

\author{
THE DISPUTE OF PUBLIC RESOURCES IN BASIC EDUCATION, THE \\ ARRANGEMENTS OF THE STATE WITH THE MARKET AND ITS IMPACTS ON \\ DEMOCRATIC AND PARTICIPATORY MANAGEMENT OF EDUCATION IN THE \\ CONTEXT OF MUNICIPALITIES
}

\author{
Rosemary Roggero \\ Doutora em Educação: História, Política, Sociedade (PUCSP) \\ Docente dos PPGE e do PROGEPE - UNINOVE \\ rosemaryr@uni9.pro.br \\ Adriana Zanini da Silva \\ Doutora em Educação (UNINOVE) \\ Docente da Rede Municipal de Santo André - SP \\ azaninidasilva@yahoo.com.br
}

\begin{abstract}
Resumo: Este trabalho analisa o financiamento da educação, com foco na transferência dos recursos da Educação Básica para o setor privado e seus impactos para a gestão democrática da educação, no âmbito dos municípios. Justifica-se pelo processo de disputa em que se encontram a regulamentação no Novo Fundeb e os recursos destinados à Educação Básica brasileira, neste período de capitalismo financeiro, e pela importância do acompanhamento das tensões na regulamentação do Conselho de Acompanhamento e Controle Social (CACS) do Fundeb. A questão que se coloca é: a que está vinculado todo esse processo? Para respondê-la, considerando o objetivo e a justificativa apresentados, o trabalho se fundamenta em estudos teóricos e empíricos sobre a temática. Conclui-se que o comprovado avanço do capital em vários setores da educação básica impacta a gestão democrática e participativa da educação, no âmbito dos municípios, colocando em risco o fortalecimento da escola pública como garantia do direito constitucional à educação e como caminho para a redução das desigualdades sociais. E também que esse processo é parte do projeto neoliberal de interesse de determinados grupos nacionais e internacionais, acelerado pelo avanço de um certo radicalismo de direita no país.
\end{abstract}

Palavras-chave: CACS Fundeb; financiamento da educação básica; gestão democrática da educação; privatização da educação básica.

\begin{abstract}
This work analyzes the financing of education, with a focus on the transfer of resources from Basic Education to the private sector and its impacts on the democratic management of education, within the scope of municipalities. It is justified by the dispute process in which the regulations in the New Fundeb and the resources destined to Brazilian Basic Education are found, in this period of financial capitalism, and by the importance of monitoring the tensions in the regulations of the Monitoring and Social Control Council (CACS) of Fundeb. The question that arises is: to what is this whole process linked? To answer it, considering the objective and justification presented, the work is based on theoretical and empirical studies on the subject. It is concluded that the proven advance of capital in various sectors of basic education impacts the democratic and participatory management of education within the municipalities, putting at risk the strengthening of public schools as a guarantee of the constitutional right to education and as a way to reduce of social inequalities. And also that this process is part of the neoliberal project of interest to certain national and international groups, accelerated by the advance of a certain rightwing radicalism in the country.
\end{abstract}

Keywords: CACS Fundeb; basic education financing; democratic management of education; privatization of basic education.

Para citar - (ABNT NBR 6023:2018)

ROGGERO, Rosemary; SILVA, Adriana Zanini da. A disputa dos recursos públicos da educação básica, os arranjos do estado com o mercado e seus impactos na gestão democrática e participativa da educação no âmbito dos municípios. Eccos Revista Científica, São Paulo, n. 58, p. 1-17 e20847, jul./set. 2021. Disponível em: https://doi.org/10.5585/eccos.n58.20847. 


\section{Introdução}

O financiamento educacional procedente das demandas de acesso, qualidade e gestão democrática é condição para que o Brasil garanta o direto à Educação, como bem posto na Constituição Federal de 1988, pois o financiamento é o eixo determinante para a implementação das políticas públicas, especialmente, em âmbito municipal.

Dados indicam que recursos educacionais adequados contribuem fortemente para impulsionar a diminuição das desigualdades educacionais e sociais. Campanha (2020), Cara (2012), Ximenes (2015), Araújo (2016) e Pinto (2018) estão entre os autores que destacam que o financiamento da educação é um dos eixos para o avanço social, econômico e político de uma nação. Estudos de Adrião, Garcia e Azevedo (2017), Arretche (1996), Dawbor (2017), Harvey (2011, 2018), Pinto (2018) Vieira e Vidal (2015), dentre outros, ainda que diversos nos seus enfoques, permitem afirmar que desde a sua origem, o financiamento da educação brasileira tem estado atrelado aos interesses econômicos das classes hegemônicas e atravessado por interesses diversos, não raro antagônicos.

Para Harvey (2018) e Dowbor (2017), em todo o mundo contemporâneo, com intensa influência do pensamento neoliberal, a educação é vista, como um grande negócio, com vários nichos de mercado pautados pela globalização. Harvey (2011), ao analisar as recentes transformações econômicas, culturais e suas influências na sociedade contemporânea, também destaca que o neoliberalismo incentiva a diminuição da presença do Estado nos investimentos sociais, por meio da contenção, da diminuição dos montantes de recursos investidos e, especialmente, do aumento da transferência de recursos ao setor privado.

Parra; Cruz; Amiel e outros (2018) também alertam para a entrada do setor privado na educação básica, com destaque ao avanço da lógica de monetização de grandes empresas sobre a educação pública, o que coloca em risco a privacidade de dados de alunos e professores, direcionam a aprendizagem, o desenvolvimento das pessoas e transformam a sociedade:

\footnotetext{
Um processo de concentração, pouco investigado, está ocorrendo na área das tecnologias educacionais e acadêmicas. Algumas poucas empresas começam a controlar a oferta de produtos e serviços de comunicação para universidades, faculdades, institutos de pesquisa e redes de educação básica. No Brasil já existem algumas universidades, institutos e faculdades públicas, comunitárias e privadas com parcerias com a Google10 e a Microsoft. Algumas Secretarias Estaduais e Municipais da Educação também têm estabelecido parcerias para oferecer os aplicativos dessas empresas para seus funcionários e estudantes (PARRA; CRUZ, AMIEL e outros, 2018, p. 69)
}

Segundo Lindh e Nolin (2016), os governos, desde a década de 1990 se tornaram cada vez mais pressionados a transformar os bens públicos em bens privados e a adoção pelo poder 
público das ferramentas digitais das grandes corporações deve ser vista no contexto do mercado ao redor da reforma na educação pública. (LINDH e NOLIN, 2016)

No Brasil, nas últimas décadas, a disputa privada pela educação pública e seus recursos tem ganhado espaço por meio da regulamentação legal, seja em âmbito nacional como local e, em tempos de crise sanitária com flexibilização orçamentária, de avanços de um novo radicalismo de direita (ADORNO, 2020) e de ameaças ao direito à educação, postulados principalmente, pela Emenda 95 de 2016, que determina que o investimento em educação não poderá exceder o ajuste inflacionário até o ano de 2036, sacrificam-se as garantias constitucionais dos direitos sociais, coloca-se em risco a implementação dos planos nacional, estaduais e municipais de Educação e os princípios acordados na reabertura democrática dos anos 1980 e expressos na Constituição Federal de 1988. Destaca-se a efetivação de cortes expressivos nos gastos da educação: em 2019, foram cerca de R \$ 32,6 bilhões; em 2021, foi aprovado um corte de 27\% aprovado na Lei Orçamentária Anual. (CAMPANHA, 2021)

Nesse contexto, o que se entende por gestão democrática também precisa ser pensado, pois é comum reduzir a participação de toda a comunidade educacional - em particular, as comunidades escolares, na decisão e no acompanhamento das receitas e despesas, que nem sempre correspondem a práticas inclusivas, participativas e democráticas.

Embora vigorem a Lei da Transparência (LC 131/2009, criada para divulgar em tempo real a receita e despesas de toda entidade pública, com o prazo máximo de $24 \mathrm{~h}$, em site na internet); e a Lei de Acesso à Informação (L 12.527/2011, que dispõe sobre como os entes federados devem disponibilizar com objetividade e agilidade o acesso às informações previstas em dispositivos constitucionais específicos nos artigos $5^{\circ}$., 37 e 216), na prática, o que se vê é uma dificuldade de acesso e compreensão na informação disponibilizada de forma complexa, pouco objetiva, pouco prática e, portanto, pouco acessível.

Este artigo tem como objetivo analisar o financiamento da educação com foco na transferência dos recursos da educação básica para o setor privado e seus impactos para a gestão democrática da educação no contexto do capitalismo financeiro, de vigilância e da crise sanitária, em função da pandemia de Covid 19.

Essa abordagem se justifica pelo processo de disputa em que se encontra o financiamento da educação básica brasileira, sobretudo neste período complexo, e pela importância do acompanhamento dos interesses e das tensões na regulamentação do Novo Fundeb, em especial a questão do Conselho de Acompanhamento e Controle Social (CACS).

Para tanto, desenvolvemos a abordagem em duas seções: O financiamento da educação básica nos municípios e A disputa dos recursos públicos pelo setor privado. 


\section{O financiamento da educação básica nos municípios}

A Constituição Federal de 1988 (CF/88) e, principalmente, as emendas constitucionais procedentes da reforma do Estado brasileiro de 1995, subsidiaram os novos ordenamentos das políticas de financiamento da Educação Básica, incidindo principalmente sobre os estados e municípios. No caso da Carta Magna brasileira, observamos a contraposição entre a garantia dos direitos, fruto das discussões que a aprovaram, e retrocessos, fruto da influência dos interesses do capital que direcionaram a reforma do Estado brasileiro. (SILVA, 2021)

Somada à CF/88, a Lei Federal nº 9.394, de 20 de dezembro de 1996, que dispõe sobre as Diretrizes e Bases da Educação Nacional. (LDB 9394/96) estabeleceu a divisão de responsabilidades entre os entes federados, a vinculação constitucional dos recursos, a retomada das políticas de fundos, o controle social dos gastos, a municipalização, a definição das despesas com Manutenção e Desenvolvimento do Ensino (MDE), a ação supletiva e redistributiva da União e o padrão de qualidade, dentre outros aspectos que foram fundamentais à construção e manutenção das redes de ensino, em especial as municipais, nosso interesse neste artigo.

Destaca-se que a sub vinculação dos recursos por meio das políticas de fundos ${ }^{1}$, em 1996, levou à criação Fundo de Manutenção e Desenvolvimento do Ensino Fundamental e Valorização do Magistério (Fundef) e, a partir de 2006, o Fundo de Manutenção e Desenvolvimento da Educação Básica e Valorização dos Profissionais da Educação (Fundeb), como grandes indutores das políticas de Educação Básica, constituindo a principal fonte de financiamento e de busca de equalização das oportunidades educacionais, responsável pela manutenção de muitas redes municipais e estaduais de ensino - ainda que com problemas a serem sanados, quanto à distribuição dos recursos.

A aprovação do Novo Fundeb, por meio da EC 108, de 26 de agosto de 2020 e regulamentado pela Lei 14.113, de 25 de dezembro de 2020, se apresenta relevante por sua constitucionalização - o que a torna uma política de estado e pode permitir o fortalecimento das redes municipais de ensino e a diminuição das desigualdades educacionais; por aprimorar a distribuição de recursos, por meio do sistema híbrido que mantém os critérios e os percentuais de distribuição do atual fundo, mas aumenta a complementação anual da União ao fundo de $10 \%$ para $23 \%$, gradualmente até 2026 ; por aperfeiçoar a distribuição da complementação da União no Novo Fundeb e por constitucionalizar, também, o Custo Aluno Qualidade (CAQ). É relevante apontar, no entanto, que esses elementos ainda precisam de regulamentação específica, o que mantém as disputas em campo.

As políticas de fundos da educação, de natureza contábil e redistributiva, reúnem grande parte da vinculação da receita dos impostos dos estados, distrito federal e municípios para serem usados em aspectos específicos e considerados prioritários. (ARAÚJO, 2016) 
É possível observar que muitos dos gastos da Educação Básica são centralizados em programas indutores propostos pelo governo federal, como a compra de livros didáticos, programa de alimentação escolar, apoio ao transporte escolar, informática na educação, dentre outros. Também é possível observar que grande parte das decisões sobre os gastos são centralizadas nas Secretarias de Educação municipais e estaduais, desde a construção e reformas das escolas, passando pela compra de material escolar, livros, brinquedos e mesmo o transporte escolar oferecido em determinadas circunstâncias, e, ainda, ao pagamento de pessoal próprio ou terceirizado.

Por outro lado, de modo geral, quando se trata do tema financiamento da educação e dos recursos descentralizados aos municípios, não há discussões e acompanhamento pelas escolas sobre as receitas e despesas, nem mesmo sobre os gastos do Fundeb, apesar dos Conselhos de Acompanhamento instituídos em cada município, os quais tendem a restringir-se a verificações burocráticas do gasto já realizado, nem sempre compatível sequer com os Planos Municipais de Educação.

No caso dos recursos que chegam às escolas por meio do Programa Dinheiro Direto na Escola (PDDE) ou por meio de convênios entre as prefeituras e as Unidades Executoras das Escolas, estes são voltados a pequenos gastos e pequenas manutenções e projetos. Apesar disso, há queixas dos professores, gestores e conselheiros sobre excesso de burocracia; extensa regulamentação legal e dificuldades de acesso ao apoio técnico centralizado, seja do governo federal, estadual ou municipal, conforme o projeto; prazos apertados para gastar e prestar contas; inadequação da destinação obrigatória dos valores em relação às necessidades das escolas; e descompasso entre os recursos locais disponíveis e as responsabilidades. (ROGGERO e SILVA, 2019)

Por outro lado, há ênfase à gestão democrática e participativa dos recursos que a escola recebe, os quais, apesar das restrições quanto à destinação, devem ser discutidos com o Corpo Docente, com o Conselho de Escola e com a Associação de Pais e Mestres, em especial.

Experiências descritas por muitos gestores (ROGGERO; SILVA, 2019; ROGGERO; COSTA; PISANESCHI, 2020) também revelam que falta discussão sobre os padrões mínimos de qualidade na aplicação dos recursos e que há significativas diferenças na compreensão da utilização e nas práticas e procedimentos adotados - o que leva a desperdício de recursos, como é o recorrente caso de livros e materiais escolares (SOUZA, 2017) ou à devolução de valores não gastos, em razão de temores de gestores escolares com os procedimentos de prestação de contas, dentre outros problemas que se observam nas formas de burlar as regras para garantir condições de utilização de determinados valores (KUBO, 2021). 
Esses dados revelam fortes contradições em relação ao que se entende por gestão democrática e participativa, assim como a continuidade de práticas de patrimonialismo e compadrio (SCHWARCZ; STARLING, 2018; SHWARCZ, 2019) no âmbito das relações entre escolas e comunidades, realidade que expõe o autoritarismo brasileiro e as dificuldades de transformação social em direção à emancipação de velhos padrões e para autonomia. Mas esses processos ficam escamoteados e intrincados em procedimentos burocráticos.

Aos supostos avanços em relação ao financiamento, em sua especificidade, na descentralização de recursos financeiros, não têm correspondido, portanto, práticas efetivamente inclusivas, participativas e democráticas. Até mesmo, os conselhos municipais e estaduais de educação não têm sido eficientes neste acompanhamento e orientações, talvez porque se mantêm muito descolados da realidade das escolas, funcionando não raro, como órgãos sem grande representatividade junto às suas comunidades.

Como já mostravam os estudos de Arretche (1996), a participação ainda tende a ser restrita e a decisão centralizada, inclusive pelas escolas, e a descentralização pode adotar o caráter de transferência de responsabilidades sem incidir sobre a democratização dos poderes decisórios, assumindo, isso sim, o caráter centralizador e de subordinação hierárquica, destacado por Harvey (2011) e descrito por Schwarcz e Staling (2018) no que se refere às peculiaridades brasileiras.

A relação entre os recursos recebidos pelos municípios e escolas, seus processos participativos e o objetivo de garantia do padrão mínimo de qualidade, assumidos no Plano Nacional de Educação e no Novo Fundeb (por meio do CAQ) ainda não estão claras para os gestores educacionais, para os gestores escolares, para educadores em geral, nem garantidas para os estudantes.

A democratização das informações das receitas e despesas é condição para o direito à educação, uma vez que os CACS do Fundeb, com pouca representatividade não são suficientes para garantir as aplicações legais, seja pelo caráter técnico, pelas disputas internas, falta de informações aos conselheiros, falta de formação ou mesmo pouca atuação, o que mostra não só o caráter burocrático, mas também o caráter plutocrático ${ }^{2}$ presente no acompanhamento e controle do gasto público. Essa realidade reforça a urgência da definição dos padrões mínimos de qualidade, por meio do CAQ, dos conselhos estaduais e municipais de educação, cuja informação deve expandir-se para todas as redes e para toda a sociedade, para o direcionamento 
dos gastos e aprimoramento do seu controle, no que concordamos com Campanha (2019), Araújo (2016), Ximenes (2015), Carreira e Pinto, R. (2006), no que se refere ao fato de que o que existe atualmente contribui muito mais aos interesses de grupos privados, que encontram portas abertas na disputa por recursos públicos da educação, fator que discutimos na próxima seção.

\section{A disputa dos recursos da educação básica pelo setor privado}

As mudanças contemporâneas do capitalismo, sob a lógica neoliberal, vêm induzindo novas relações entre o Estado e a sociedade. $\mathrm{O}$ aumento das transações financeiras que se deram em função da liberação, desregulação dos mercados e das atividades financeiras pelos governos, desde os anos 1990, possibilitou o fortalecimento dos sistemas especulativos em detrimento dos produtivos, resultando na financeirização da economia. Esse modelo tem impactado a sociedade, à medida que a especulação rende mais do que a produção, o que tem como consequências, entre outras, o desemprego, que diminui os rendimentos salariais e amplia as desigualdades sociais. (DOWBOR, 2017).

Incentivada pelos países centrais, por meio de acordos com os organismos internacionais, a financeirização representa uma alteração na configuração do sistema capitalista, que enxerga a educação como mercadoria a ser comercializada, defende a lógica da eficiência e da competição à moda empresarial; estimula a concorrência e a privatização, por meio de avaliações em larga escala (que não referem as especificidades do processo educacional) e ranqueamentos inúteis à melhoria da qualidade da educação (visto que não alcançam os avanços esperados desde que criados); controla a produção do conhecimento por meio das demandas muito específicas dos setores produtivos (com pouco financiamento e condições de trabalho adversas e questionáveis); pressiona o sistema público a diminuir os gastos com a educação, argumentando pela eficácia e desconsiderando as desigualdades sociais nacionais e regionais); e direciona a implementação de uma política compensatória para diminuir a tensão social e conter conflitos, mas não diminuir as desigualdades.

No bojo desse complexo, ainda se vê as recomendações para a regulação da política educacional brasileira, por meio de diagnósticos, propostas para a reorganização curricular, a gestão, a avaliação e o próprio financiamento da educação, apontando para uma transferência cada vez maior de recursos para o setor privado, como se vê na questão das creches conveniadas (SILVA,G.S., 2020). 
Essa disputa pelo destino dos recursos da educação têm tirado percentuais significativos da educação pública, confirmando, cada vez mais, a correlação de forças existentes entre os interesses do capital e a garantia de direitos constitucionais.

$\mathrm{Na}$ educação brasileira, os marcos regulatórios, a CF/88, em seu artigo 213 e a LDB 9394/96, em seu artigo 77, permitem o repasse do dinheiro público às escolas comunitárias, confessionais ou filantrópicas sem fins lucrativos. No entanto, o problema central se encontra no caráter "não lucrativo" das escolas comunitárias, confessionais e filantrópicas, pois são muitos os artifícios contábeis para conferir o caráter não lucrativo às mesmas, conforme constata Davies (2012), sem contar a fragilidade encontrada nos mecanismos de controle das prestações de contas de instituições conveniadas (SILVA, G.S, 2020). A legislação brasileira também prevê o repasse do dinheiro público ao ensino privado quando aprova no artigo 70 , inciso VI da LDB 9394/96, a concessão de bolsas de estudo aos alunos de escolas privadas, hoje estabelecidas principalmente pelo Fundo de Financiamento Estudantil (FIES) e pelo Programa Universidade para Todos (PROUNI), mas defendida por vários governos brasileiros na linha dos vouchers, conforme indica Cavalcante (2018), para quem fica clara a intenção de enxugamento das responsabilidades e funções estatais, tendo em vista a convergência que se apresenta nas redes de parceria e colaborações, na atuação em sociedades complexas a plurais como as atuais, que pode se materializar pelo compartilhamento de atividades e funções com o setor privado.

A aprovação de legislações específicas como a Lei nº 8.666, de 1993 que versa sobre os processos de licitação em contratos da administração pública; a Lei nº 9.637 de 1998, que dispõe sobre a qualificação das entidades como Organizações Sociais (OS) e a Lei nº 13.243 de 2016, que dispõe sobre estímulos ao desenvolvimento científico, à pesquisa, à capacitação científica e tecnológica e à inovação, dentre outras, também abriram caminhos que aprofundaram a saída do dinheiro público para as parcerias público privadas.

Adrião e Domiciano (2018) também retratam a força do capital na educação por meio dessa simbiose construída entre os governos e segmentos do setor privado corporativo. As autoras informam que, no Brasil, o financiamento público às instituições privadas se materializa, recentemente, por meio de contratos, convênios, termos de parceria e de cooperação. Na Educação Básica, principalmente, na Educação Infantil por repasse per capita, como subvenção governamental por aluno matriculado, mantendo a frequência gratuita; e repasse de um valor fixo, quando a subvenção repassada à instituição privada não tem relação com a matrícula e custeio de itens de manutenção da escola, como cessão de prédios, de funcionários e insumos variados. Ainda que essa "tipificação" se refira predominantemente à 
Educação Infantil (ADRIÃO, 2018, p. 13), tais formas encontram-se vigendo para as demais etapas de escolaridade, como recursos para ampliação do currículo na educação integral ou oferta de cursos rápidos supostamente profissionalizantes, para jovens e adultos. A concessão de subvenções, de empréstimos a juros subsidiados ou a fundo perdidos e a isenção de impostos também têm favorecido o ensino privado com recursos públicos.

Adrião (2018) também destaca que há formas indiretas de financiamento público às instituições privadas de ensino por meio de adoção de créditos fiscais reembolsáveis para as empresas ou às famílias. Na privatização da oferta da Educação Básica, principalmente na Educação Infantil, os subsídios públicos mais comuns são convênios, contratos e bolsas de estudo financiadas com recursos de MDE ou formas de atendimento educacional por provedores privados custeadas por fundos públicos (como os vouchers mencionados acima). Na privatização da gestão educacional, há contratação de assessorias, transferências da gestão escolar para instituições privadas, sistemas de avaliação e bônus por produtividade aos trabalhadores da educação. Para isso, as avaliações em larga escala e ranqueamentos servem ao propósito de desqualificação do modelo de gestão pública societal (PAULA, 2005).

Adrião e Garcia (2018) analisaram a destinação de recursos federais, no período de 2002 a 2014, quando se ampliaram os gastos com a educaçãoem relação ao PIB e ao período de escolaridade obrigatória. Apenas para ficar no último ano da pesquisa, em 2014, o setor educacional movimentou três bilhões de reais e respondeu por $85 \%$ dos investimentos de 113 investidores privados, mas:

Ainda assim, estudos identificaram a atuação do setor privado junto aos sistemas
públicos de ensino, tanto para a oferta da Educação Básica, financiada com recursos
públicos por meio de parcerias público-privado, como o caso de Belo Horizonte
(ADRIÃO; BEZERRA, 2013); de escolas em concessão ou conveniadas (BORGHI et
al., 2012; ADRIÃO, 2014; DOMICIANO; 2016; FRANCO, 2015; PINTO, R.; 2014),
quanto para a venda de insumos curriculares por corporações. Destaca-se a venda de
livros didáticos, apostilas ou tecnologias de informação em geral; de sistemas de
gestão envolvendo sistemáticas de avaliação de desempenho de estudantes e de
escolas; de programas de qualificação de professores; de assessorias para a gestão [...]
(ADRIÃO; DOMICIANO, 2018, p. 3).

Além disso, a importância dada aos resultados e à busca da eficiência a qualquer custo, enfraqueceu o princípio do respeito às diferentes necessidades dos alunos no processo educativo; enfraqueceu o princípio da educação como um bem público, como um meio de desenvolvimento integral do ser humano em todas as dimensões do conhecimento e como um direito social, apesar de documentos e discursos alegarem o contrário. A educação é mensurada e regulada como uma mercadoria e submetida à política econômica, como nunca antes, em benefício do mercado. 
Para Laval (2004, p.14,15) muitas tomadas de decisão do Estado se justificam para o enfrentamento das crises econômicas, no entanto, elas limitam a expansão das políticas sociais em favor do capital: Muito mais do que uma "crise" passageira é a mutação do capitalismo que assistimos. A aposta crucial é o enfraquecimento de tudo ao que faz contrapeso ao poder do capital e de tudo o que, institucional, juridica e culturalmente, limita sua expansão e reprodução.

Em 1999, o documento A Educação para a América Latina e Caribe (BANCO MUNDIAL, 1999), que dispunha sobre a avaliação da educação na década de 1990 e das diretrizes para o século XXI, já destacava a educação como estratégia para alívio da pobreza, articulada ao setor privado, com foco, principalmente, nas universidades, propondo reordenamentos que impulsionaram o processo de ampliação da privatização da educação superior, no caso do Brasil.

Em 2002, o documento - Construir sociedades del conocimiento: nuevos desafíos para la educación terciária, permitiu intensificar a mercantilização da educação superior brasileira e, mesmo que em proporções e intencionalidades diferenciadas, conforme já apontado, abriu as portas para a privatização nos demais níveis de ensino

Nesse contexto, Krawczyk (2002, p.45) analisa três dimensões das reformas educacionais proposta pelo Banco Mundial (BM) aos países periféricos, dentre as quais está a dimensão política, que apresenta as recomendações aos governantes às reformas educacionais, cujo principal alvo é o compromisso com o setor privado, com "[...] destaque para as leis que regulamentam a participação empresarial, e das fundações privadas, estabelecendo-se mecanismos de aproximação entre o setor público e o setor privado no âmbito educacional", com benefícios tributários e concessões.

Nos discursos políticos correntes, as parcerias e concessões ao setor privado são justificadas para resolver os problemas das escolas, professores e gestores da educação pública, concomitante, disseminam a ideia de que o setor privado está preparado para enfrentar e acabar com a crise da educação pública, uma articulação engenhosa para transferir o dinheiro público para o setor privado. Interessante notar que, mesmo com a invasão que vai se dando pelo setor privado sobre o público, os índices educacionais não apresentam melhora.

Fatorelli (2013, p.32) também alerta que a atuação do BM e do Fundo Monetário Internacional (FMI) é para a “[...] redução de gastos sociais com serviços públicos; redução de investimentos públicos; realização de antirreformas nos sistemas trabalhistas, tributário e previdenciário; privatizações; modificação de diversos textos legais em benefício do setor privado", o que coaduna, no Brasil, com a Reforma Trabalhista, a Reforma da Previdência, a EC 95/2016. Além disso, pode ser observado, desde as últimas eleições presidenciais, todo um 
processo de radicalização da direita, bastante convenientes a uma aceleração do projeto neoliberal.

Os currículos das escolas brasileiras também sofrem interferência das orientações do BM e das corporações privadas, a começar pela construção da Base Nacional Comum Curricular (BNCC), conduzida pelo Movimento pela Base, coordenada pela Fundação Lemann, por meio do Lemann Center, vinculado à Universidade de Stanfort-USA; pela Curriculum Foundation, instituição inglesa; Accara, instituição australiana e Phill Daro e Susan Pimentel que atuaram no Comonn Core americano, além de Sheila Byrd Carmichael, que assinam a avaliação da BNCC brasileira, conforme investigação de Peroni; Caetano e Arelaro (2019).

A BNCC denota o jogo de forças entre o direito à educação garantido na $\mathrm{CF} / 88$ e as expectativas de aprendizagem focadas nos resultados das avaliações externas. De um lado, o direito à educação está associado à melhoria nas condições de trabalho do professor, infraestrutura adequada das escolas, participação das famílias, número de alunos apropriado por sala de aula, recursos adequados, dentre outros que compõem proposta de indicadores de qualidade para a educação. De outro lado, as expectativas de aprendizagem associadas ao aumento da produtividade no trabalho e a ampliação da competitividade, tocando no financiamento apenas como revisão e adequação dos gastos.

A BNCC revela a articulação do grande capital com as Organizações Internacionais, alinhando possibilidades de parceria das fundações e institutos empresariais com a educação pública e evidenciando que a Educação Básica se tornou o foco do mercado - "terra virgem a ser explorada", como diz Bauman, em Capitalismo Parasitário (2010) . No cotidiano escolar, essa interferência se dá por meio de apostilas, materiais de orientação aos docentes, planejamento de aulas, cursos e, até mesmo, na formação dos docentes com orientações para as suas práticas, incidindo fortemente sobre o planejamento curricular e transformando os profissionais da educação em executores de propostas padronizadas, como já se observa em muitos municípios, há vários anos.

Fruto da pesquisa sobre o mapeamento das estratégias de privatização da Educação Básica no Brasil, Adrião e Garcia (2018), apresentam um número crescente de programas privados que incidem sobre o currículo nas escolas brasileiras, bem como, o número e a natureza dessas instituições privadas, sua incidência nas etapas de ensino e o seu público alvo. Das 395 instituições privadas em 243 programas que incidem nos currículos das escolas brasileiras, a maioria encontra-se na região Nordeste, seguida da Sudeste. O aumento dessa incidência no currículo brasileiro por meio da BNCC, do Programa Nacional do Livro Didático (PNLD) e das avaliações externas chama a atenção e preocupa, pois não atende aos princípios 
de uma educação integral focada no desenvolvimento dos diferentes aspectos que contribuem à formação humana; e, sim, fragmenta a educação e seu currículo para a formação da mão de obra barata, o que não faz sentido em relação ao aumento de produtividade do trabalho, por isso parece escamotear interesses ainda mais perversos, como a produção de um lumpemproletariado, como concluem as pesquisas de Cardoso (2015; 2019), de Melo (2020), de Kubo (2021) e de Almeida (2021) entre muitas outras.

Os benefícios legais e fiscais da educação privada são reforçados pela Reforma do Estado e pelas influências das grandes corporações, tendendo a substituir as organizações públicas por empresas privadas, organizações sociais de direito privado e fundações, com o falso discurso de que o problema refere-se à gestão dos recursos e à qualidade dos serviços prestados:

\begin{abstract}
A nova retórica de descentralização que pretende estimular a participação da sociedade na esfera política tem como finalidade aproximação entre financiamento e administração, tanto nas relações do poder público com o mercado, quanto na transferência de responsabilidade para os municípios e para a escola, no caso da educação. Assim, pode se justificar a restrição do financiamento público para a educação, alegando-se que os problemas educacionais não decorrem da falta de recursos, mas da falta de uma melhor administração desses recursos. (ADRIÃO e PERONI, 2007, p.49).
\end{abstract}

Concordamos com Bianchetti (1997), que a descentralização poderia ser considerada uma estratégia para fortalecer e consolidar a democracia por meio da influência de diferentes sujeitos no planejamento, nas tomadas de decisão e no controle das políticas públicas, garantindo autonomia às bases e mudanças nas relações de poder, inclusive nas políticas públicas de financiamento da Educação Básica. Esta compreensão permite a participação de todos os sujeitos nos processos decisórios, defende o fortalecimento das instâncias locais, a participação de diferentes atores no planejamento, na implementação e na avaliação das políticas públicas, sendo uma possibilidade para o fortalecimento de ações democráticas que se espera ter na regulamentação do CAQ e nas ações do CACS do novo Fundeb.

\title{
Considerações finais
}

As diversas pesquisas teóricas e empíricas tomadas para a elaboração deste artigo apontam na direção de que o capitalismo em sua etapa de financeirização e com seu caráter parasitário, avança para a educação como um todo - no caso do enfoque deste artigo, em especial na educação básica - por meio da articulação de diversos mecanismos que incluem a escola em todos os seus recursos físicos, virtuais, digitais, seu currículo, suas metodologias, a formação inicial e continuada de professores e gestores, a organização de procedimentos 
burocráticos, a avaliação de processos e resultados, assim como as relações que constrói com a sociedade, de forma inédita, e pautada especialmente na destinação dos recursos financeiros.

Nosso recorte conceitual e analítico aponta para o lado em que nos encontramos no espectro do debate sobre o tema e nos leva a concluir que aquilo que foi possível confirmar, nesse recorte, comprova o avanço do capital em vários setores da educação básica de modo a impactar a gestão democrática e participativa da educação.

Esse processo, atomizado no âmbito dos municípios, coloca em risco o fortalecimento da escola pública como garantia do direito constitucional à educação e como caminho para a redução das desigualdades sociais - o que tem feito parte de um projeto progressista de país, desde a abertura democrática, pós ditadura militar, que vigorou de 1964 a 1985.

Por outro lado, apresenta-se, claramente, como parte do projeto neoliberal de interesse de determinados grupos nacionais e internacionais, acelerado pelo avanço de um certo radicalismo de direita no país. Essa questão precisa ser compreendida e debatida publicamente, pelos educadores e pela sociedade, porque está avançando um projeto de país e de formação humana, que reverberará por décadas.

\section{Referências}

ADORNO, Theodor. Aspectos do novo radicalismo de direita. São Paulo: Editora Unesp, 2020.

ADRIÃO, Theresa e PERONI, Vera Maria Vidal. Programa Dinheiro Direto na Escola: Uma proposta de redefinição do Estado na educação? Brasília: Instituto Nacional de Estudos e Pesquisas Educacionais Anísio Teixeira, 2007. 204 p.

ADRIÃO, Theresa e PERONI; GARCIA, T.; AZEVEDO, J. P. Compulsory education in Brazil: privatization trends and limits the right to education. problems of education in the twenty first century, Journal Problems of Education in the 21st Century, v. 75 (4), p. 324-334, ago. 2017.

ADRIÃO, Theresa e PERONI; DOMICIANO, Cassia Alessandra. A Educação Pública e as Corporações: avanços e contradições em uma década de ampliação de investimento no Brasil. FINEDUCA - Revista de Financiamento da Educação, Porto Alegre, v. 8, n. 3, 2018.

ADRIÃO, Theresa e PERONI; GARCIA, T. (orgs). Currículo, Gestão e oferta da Educação Básica brasileira: incidência de atores privados nos sistemas estaduais (2005-2015). Coleção estudos sobre a privatização da educação no Brasil. Curitiba: CRV, 2018.

ALMEIDA, Sandy Katherine Weiss. O Diretor de Escola e a Gestão Escolar: formação e práticas em escolas municipais paulistanas. Dissertação de Mestrado. Orientadora: Rosemary Roggero. São Paulo: Uninove, 2021 
ARAÚJO, Luiz. O CAQi e o novo papel da União no financiamento da Educação Básica. Jundiaí: Paco Editorial, 2016. 300p.

ARRETCHE, Marta Teresa da Silva. O Mito da Descentralização: Maior Democratização e Eficiência das Políticas Públicas? Revista Brasileira de Ciências Sociais, ANPOCS, n.31, 1996.

BANCO MUNDIAL. Relatório do Desenvolvimento Mundial 1998/1999: El conocimiento al servicio del desarrollo, Washington, DC, 1999.

BANCO MUNDIAL. Construir sociedades del conocimiento : nuevos desafíos para la educación terciaria. Washington, 2003. ISBN 958-96760-8-1. Disponível em: https://documents.worldbank.org/pt/publication/documentsreports/documentdetail/287031468168578947/construir-sociedades-del-conocimientonuevos-desafios-para-la-educacion-terciaria. Acesso em: 17 jun. 2021.

BRASIL. [Constituição (1988)]. Emenda Constitucional 108, de 26 de agosto de 2020. Dispõem sobre o Fundo de Manutenção e Desenvolvimento da Educação Básica e de Valorização dos Profissionais da Educação (Fundeb); altera o Ato das Disposições Constitucionais Transitórias; e dá outras providências. Diário Oficial da República Federativa do Brasil, Brasília, DF, 27 de ago. 2020. Seção 1, p.5.

BRASIL. [Constituição (1988)]. Emenda Constitucional n.95, de 15 de dezembro de 2016. Altera o Ato das Disposições Constitucionais Transitórias, para instituir o Novo Regime Fiscal, e dá outras providências. Diário Oficial da República Federativa do Brasil, Brasília, DF, 15 dez. 2016. Seção 1, p. 2.

BRASIL. Lei Federal $n^{o} 13.243$, de 11 de janeiro de 2016. Dispõe sobre estímulos ao desenvolvimento científico, à pesquisa, à capacitação científica e tecnológica e à inovação e altera a Lei $\mathrm{n}^{\circ} 10.973$, de 2 de dezembro de 2004, a Lei $\mathrm{n}^{\circ}$ 6.815, de 19 de agosto de 1980, a Lei ${ }^{\circ}$ 8.666, de 21 de junho de 1993, a Lei ${ }^{\circ} 12.462$, de 4 de agosto de 2011, a Lei $n^{\circ} 8.745$, de 9 de dezembro de 1993, a Lei $\mathrm{n}^{\circ}$ 8.958, de 20 de dezembro de 1994, a Lei $\mathrm{n}^{\circ} 8.010$, de 29 de março de 1990, a Lei $n^{\circ} 8.032$, de 12 de abril de 1990, e a Lei ${ }^{\circ} 12.772$, de 28 de dezembro de 2012, nos termos da Emenda Constitucional no 85, de 26 de fevereiro de 2015. Disponível em: http://www.planalto.gov.br/ccivil_03/_ato2015-2018/2016/lei/113243.htm. Acesso em: 18 jun. 2021.

BRASIL. Lei $n^{\circ}$ 12.527, de 18 de novembro de 2011. Regula o acesso a informações previsto no inciso XXXIII do art. $5^{\circ}$, no inciso II do $\S 3^{\circ}$ do art. 37 e no $\S 2^{\circ}$ do art. 216 da Constituição Federal; altera a Lei $n^{\circ} 8.112$, de 11 de dezembro de 1990; revoga a Lei $n^{\circ}$ 11.111, de 5 de maio de 2005, e dispositivos da Lei $\mathrm{n}^{\circ}$ 8.159, de 8 de janeiro de 1991; e dá outras providências. Disponível em: http://www.planalto.gov.br/ccivil_03/_ato20112014/2011/lei/l12527.htm. Acesso em: 18 jun. 2021.

BRASIL. Lei Complementar $n^{\circ} 131$, de 27 de maio de 2009. Acrescenta dispositivos à Lei Complementar $n^{\circ} 101$, de 4 de maio de 2000, que estabelece normas de finanças públicas voltadas para a responsabilidade na gestão fiscal e dá outras providências, a fỉm de determinar a disponibilização, em tempo real, de informações pormenorizadas sobre a execução orçamentária e financeira da União, dos Estados, do Distrito Federal e dos 
Municípios. Disponível em: . http://www.planalto.gov.br/ccivil_03/leis/lcp/lcp131.htm Acesso em: 18 jun. 2021.

BRASIL. Lei Federal n ${ }^{\circ}$ 9.394, de 20 de dezembro de 1996. Dispõe sobre as Diretrizes e Bases da Educação Nacional. Diário Oficial da República Federativa do Brasil, Brasília, DF, 23 dez. 1996. p. 27833.

BRASIL. Lei Federal $n^{\circ}$ 8.666, de 21 de junho de 1993. Regulamenta o art. 37, inciso xxi, da Constituição Federal, institui normas para licitações e contratos da administração pública e dá outras providências. Disponível em:

https://legislacao.presidencia.gov.br/atos/?tipo=LEI\&numero=8666\&ano=1993\&ato=beaEzY U5ENFpWTd78. Acesso em: 18 jun. 2021.

BRASIL. [Constituição (1988)]. Constituição da República Federativa do Brasil. Brasília, DF: Presidência da República. Disponível em

http://www.planalto.gov.br/ccivil_03/constituicao/constituicaocompilado.htm. Acesso em 13 jun. 2019.

BAUMAN, Zygmunt. Capitalismo Parasitário. Rio de Janeiro: Zahar, 2010.

BIANCHETT, R. G. O modelo neoliberal e as políticas educacionais. São Paulo: Editora Cortez, 1997

CAMPANHA NACIONAL PELO DIREITO À EDUCAÇÃO. Semana de Ação Mundial 2021. Disponível em: https://semanadeacaomundial.org/2021/materiais/. Acesso em: 18 jun. 2021.

CAMPANHA NACIONAL PELO DIREITO À EDUCAÇÃO. Nota Técnica EC 26/2020: Por que é imprescindível constitucionalizar o CAQ. Campanha: agosto, 2020. São Paulo: Campanha. Disponível em: https://campanha.org.br/. Acesso em 11 nov. 2020.

CAMPANHA NACIONAL PELO DIREITO À EDUCAÇÃO. Por que 7\% do PIB para a Educação é pouco? Cálculo dos investimentos adicionais necessários para o novo PNE garantir um padrão mínimo de qualidade. São Paulo: Campanha, 2011b. Disponível em: https://campanha.org.br/. Acesso em: 02 fev. 2019.

CARA, Daniel. Por Que 10\% do Pib Para a Educação Pública? A Posição da Campanha Nacional pelo Direito à Educação. Educação em Revista, Marília, v. 13, n. 1, p. 13-30, jan./jun. 2012.

CARREIRA, Denise; PINTO, R., José Marcelino Rezende. Custo Aluno-Qualidade Inicial: rumo à educação pública de qualidade no Brasil. Cortez: São Paulo, 2006.

CARDOSO, Vania Marques. Tempo para Colaborar? Olhares sobre o significado e os sentidos atribuídos pelos docentes ao horário de trabalho coletivo. Dissertação de Mestrado. Orientadora: Rosemary Roggero. São Paulo: Uninove, 2015.

CARDOSO, Vania Marques. Uma Escola Administrada para Todos: Política Pública de ampliação da Educação Básica no Brasil nas últimas quatro Décadas. Tese de Doutoramento. Orientadora: Rosemary Roggero. São Paulo: Uninove, 2019. 
CAVALCANTE, P. Convergências entre a Governança e o Pós-Nova Gestão Pública. $1^{\mathrm{a}}$ ed. Brasília: Ipea, 2018.

DAVIES, Nicholas. O financiamento da educação estatal no Brasil: novos ou velhos desafios? Revista Educação. PUC-Rio, nº10, p.31-63, 2012. Disponível em:

https://www.maxwell.vrac.puc-rio.br/20039/20039.PDF. Acesso em 10 set. 2019.

DOWBOR, Ladislau. A era do capital improdutivo: por que oito famílias tem mais riqueza do que a metade da população do mundo? São Paulo: Autonomia Literária, 2017.

FATTORELLI, Maria Lucia. Auditoria Cidadã da Dívida Pública: experiências e Métodos. Maria Lucia Fattorelli (org). Brasília: Inove Editora, 2013.

HARVEY, David. A loucura da razão econômica: Marx e o capital no século XXI. $1^{\text {a}} e d$. São Paulo: Boitempo, 2018.

HARVEY, David. O enigma do capital e as crises do capitalismo. $1^{\text {a }}$ ed. São Paulo: Boitempo, 2011.

KRAWCZYK, Nora. A sustentabilidade da reforma educacional em questão: a posição dos organismos internacionais. Revista Brasileira de Educação, n. 19, jan./mar./abr. 2002.

KUBO, Gisele Pereira. A Gramática de Participação do Diretor de Escola na Administração de Recursos Financeiros em Escolas Públicas da Cidade de São Paulo. Dissertação de Mestrado. Orientadora: Rosemary Roggero. São Paulo: Uninove, 2021.

LAVAL, Christian. A Escola não é uma empresa, o neoliberalismo em ataque ao ensino público. Londrina: Planta, 2004.

LINDH, Maria; NOLIN, Jan. Information we collect: surveillance and privacy in the implementation of Google apps for education. European Educational Research Journal, Oxford, v. 15, n. 6, p. $644-663$, jul. 2016.

MELO Emanuel Lucas Batista de. As Práticas da Progressão Continuada como Produtoras do Lumpemproletariado. Dissertação de Mestrado. Orientadora: Rosemary Roggero. São Paulo: Uninove, 2020.

PAULA, Ana Paula Paes de. Administração Pública Brasileira: entre o gerencialismo e a gestão social. eRAE. São Paulo. Vol. 45, n.1, jan./mar, 2005, pp.36-49.

PARRA, H. Z. M.; CRUZ, L.; AMIEL, T. e outros. Infraestruturas, Economia e Política Informacional: o Caso do Google Suite For Education. Dossiê - Vigilância, controle e novas tecnologias. Mediações, Londrina, v. 2, n. 1, p. 63-99, jan./jun. 2018.

PERONI V. M. V.; CAETANO M. R.; ARELARO L. R. G. BNCC: disputa pela qualidade ou submissão da educação? Revista Brasileira de Política e Administração da Educação$R B P A E$, v. 35, n. 1, p. 035 - 056, jan./abr. 2019. 
PINTO, Élida Graziane; XIMENES, Salomão Barros. Financiamento dos direitos sociais na Constituição de 1988: do "pacto assimétrico" ao "estado de sítio fiscal". Revista Educação \& Sociedade, Campinas, v. 39, no. 145, p.980-1003, out./dez. 2018.

PINTO, José Marcelino de. O financiamento da educação na Constituição Federal de 1988: 30 anos de mobilização social. Revista Educação \& Sociedade, Campinas, vol. 39, n. 145, p. 846-869, nov. 2018.

ROGGERO, Rosemary; COSTA, Ana Araújo; PISANESCHI, Lucilene C.S. (orgs.). Financiamento da Educação Básica e a escola como agência multifuncional na sociedade neoliberal. São Paulo: BTAcadêmica, 2020.

ROGGERO, Rosemary; SILVA, Adriana Zanini da (orgs). O financiamento das escolas de Educação Básica na gestão democrática e participativa. São Paulo: BT Acadêmica, 2019. SCHWARCZ, Lilia Moritz. Sobre o Autoritarismo Brasileiro. São Paulo: Companhai das Leras, 2019.

ROGGERO, Rosemary; STARLING, Heloisa M. Brasil: uma biografia. São Paulo: Companhia das Letras, 2018.

SILVA, Adriana Zanini da. O financiamento da Educação Básica no Brasil contemporâneo: avanços e contradições revelados nos gastos da educação de Santo André. 2021. Tese de Doutoramento - Orientação: Rosemary Roggero. Universidade Nove de Julho, São Paulo, 2021.

SILVA, Adriana Zanini da; ROGGERO, Rosemary. A descentralização de recursos no financiamento da educação básica. In: ROGGERO, Rosemary e SILVA, Adriana Zanini da (orgs). O financiamento das escolas de Educação Básica na gestão democrática e participativa. São Paulo: BT Acadêmica, 2019.

SILVA, Gicelia Santos. Direito e Financiamento na Educação Infantil de 0 a 3 anos - um estudo exploratório dos processos de privatização no município de São Paulo. Dissertação (Mestrado). São Paulo: Universidade Nove de Julho - UNINOVE, 2020.

SOUZA, Ana Melícia Moraes de. Formação e Sustentabilidade na Sociedade Capitalista de Consumo: a gestão do material escolar em uma escola estadual de São Paulo. Dissertação de Mestrado. Orientadora: Rosemary Roggero. São Paulo: Uninove, 2017.

VIDAL, Eloísa Maia; VIEIRA, Sofia Lerche. Política de Financiamento da educação no Brasil: uma (re)construção histórica. Revista Em Aberto, Brasília, v. 29, n. 93, p. 14-42, jan./jun. 2015.

XIMENES, Salomão Barros. Direito à educação e sistemas privados de ensino nas redes públicas: hipóteses para análise jurídica. Educação (Rio Claro. Online), v. 25, p. 563-577, 2015. Disponível em: https://doi.org/10.18675/1981-8106.vol25.n50.p563-577. Acesso em: 23 set. 2019. 